\title{
POSTERIOR C1-C2 FUSION FOR ATLANTOAXIAL ROTATORY FIXATION AFTER POSTERIOR FOSSA CRANIOTOMY IN A 4-YEAR-OLD: A CASE REPORT
}

\section{Vinicius Meldau Benites ( $\square$ vmbenites@hotmail.com )}

Universidade Federal de Sao Paulo https://orcid.org/0000-0003-1693-9357

\section{Sergio Cavalheiro}

Universidade Federal de Sao Paulo

\section{Case report}

Keywords: Atlantoaxial rotatory fixation; Atlantoaxial joint; Rotational deformity; Posterior fossa craniotomy; Cock Robin position; Cervical Spine; Halo gravity traction; C1-C2 stabilization; Harms technique; Children

Posted Date: April 12th, 2019

DOI: https://doi.org/10.21203/rs.2.9145/v1

License: (a) (i) This work is licensed under a Creative Commons Attribution 4.0 International License. Read Full License 


\section{Abstract}

Study Design: Case report Objective: This study aimed to highlight that Atlantoaxial rotatory fixation (AARF) can be related to neurosurgery procedures in children with an afterwards demonstration of good results after halo-gravity traction and C1-C2 stabilization using the Harms technique. Summary of Background Data: AARF is characterized by dislocation or subluxation of the atlantoaxial joint, leading to a rotational deformity which may cause pain. Such a condition is mostly found in pediatric patients.

Trauma, upper respiratory infections, surgery of the head and the neck, and even rheumatoid arthritis and Down syndrome have been designated as predisposing factors. It is important to note that in some cases AARF evolves with no apparent cause and to date, the choice of optimal surgical procedure should be carefully selected, considering the anatomical and bone conditions, as well as the surgeon's experience with each technique. Methods: We report the first case related, in our knowledge, of a 4-year-old boy who presented atlantoaxial rotatory fixation after a posterior fossa craniotomy to treat a cerebellar astrocytoma. Results: At our medical facility, we diagnosed AARF by plain radiograph and CT image, and he was treated with continuous cranial traction for 14 days. Initially, we detected that he had no $\mathrm{C} 1$ posterior arch or $\mathrm{C} 2$ spinous process, so our choice was to perform Harms technique. Postoperatively, the patient was placed in a cervical collar for four weeks. At him 4-years postoperative follow-up, he was doing well and did not develop any complication. Conclusion: We call the attention to the fact of AARF can be developed after neurosurgical procedures. A surgical technique to be used in Atlantoaxial subluxation should be carefully select. In our case, Harms technique after cranial traction was an excellent option to correct and stabilize the abnormal neck position presented. However, further studies are required to determine the best technique to be used in the pediatric population.

\section{Background}

Atlantoaxial rotatory fixation (AARF) is a condition characterized by cervical pain and limited motion of the neck. It was first described by Bell in 1930 and classified by Fielding and Hawkins in 1977 into four types according to the severity of displacement and the anterior or posterior position of the atlas in relation to the axis [1]. This condition has also been reported in patients following otorhinolaryngological or head and neck surgeries, and patients with disorders such as rheumatoid arthritis, Down syndrome, and Morquio syndrome [2-6]. To the best of our knowledge, this is the first case of AARF related to postoperative complications following neurosurgery.

\section{Case Presentation}

\section{History}

A 4-year-old boy was admitted to our medical facility with a complaint of abnormal neck position since he underwent surgery of the posterior fossa for excision of a cerebellar astrocytoma five months earlier under the care of another medical facility. The collected information was that the patient was prone positioned in a horseshoe head rest during the tumor resection, and it is worth noting that the other 
medical team reported no surgical or positioning accident. After three days, it was observed the neck tilt and the patient was treated as if he had torticollis or muscle contraction.

\section{Examination and Diagnosis}

The patient presented with left, anterior fixed rotation of the neck, also known as Cock Robin position, and limited rotation, flexion, extension, and lateralization of the cervical spine. He had no neurological deficit or cervical pain.

Three-dimensional computed tomography showed a type 3, left, anterior, fixed atlantoaxial rotatory subluxation according to the Fielding and Hawkins classification (Fig. 1A) and C2-C3 subluxation. The posterior arch of the atlas (C1), the spinous process, and part of the $\mathrm{C} 2$ lamina were previously surgically removed (Fig. 1B).

\section{Halo gravity traction}

Immediately after diagnosis, the patient was placed in continuous cranial traction either in a walker or in an adapted bed (Fig. 2A, B). Traction began with $2 \mathrm{~kg}$ and was increased by $250 \mathrm{~g}$ every two days. On the 14th day, we observed the alignment of the neck position and radiography showed reduced joint subluxation and joint distraction between the posterior elements of C1 and C2 (Fig.2C).

\section{Operation and Postoperative Course}

On the 15th day, we performed C1-C2 stabilization using the Harms technique (Fig.3). The absence of C1$\mathrm{C} 2$ posterior elements precluded the use of any posterior cervical wiring technique. We chose to perform the only decortication of the C1-C2 articular surfaces because of insufficient bone exposure.

The patient was discharged on the 2nd postoperative day, used a Philadelphia collar for four weeks and underwent a further investigation of collagen disorders and other medical conditions, but nothing was found. He showed progress after three months without cervical pain or any other complaint, with an only limited head rotation that persists nowadays. The radiological follow-up only with plain radiographs is recommended as it has a much lower patient dose than computed tomography (CT)[7]. Comparing pre(Fig. 4A) and postoperative (Fig.4B) images we observed a reduction of the abnormal neck position presented previously.

\section{Discussion And Conclusions}

To the best of our knowledge, this is the first case of AARF related to postoperative complications following neurosurgery. As his parents affirm that they noted the abnormal position of his head immediately after the surgery, we hypothesize that he develops the C1-C2 subluxation during any step of the cranial procedure. 
The atlantoaxial joint is a unique articulation, which is the cornerstone of the upper cervical spine and allows a large degree of the head rotation. Attempts to establish diagnostic criteria for AARF have not been successful yet because such pathological rotation occurs within the physiological range of motion [4].

The atlantoaxial joint is responsible for $60 \%$ of cervical rotation, the atlanto-occipital joint for $5-10 \%$, and the remaining rotation is shared by the subaxial segments[3]. The pathological definition of AARF is not described by the static angular relationship between $\mathrm{C} 1$ and $\mathrm{C} 2$; however, in the abnormal form, it is known that $\mathrm{C} 1$ is related to $\mathrm{C} 2$ during movement cycles in axial rotation [3].

Part III of Pang and Li's study of AARF [8] describes a slight tendency for younger children to have a more severe $\mathrm{C} 1-\mathrm{C} 2$ interlock and the severity was related to length of pretreatment time, although this difference was not statistically significant.

We perform continuous cranial traction because such treatment aims to stabilize the joint, and stimulate normal sagittal and coronal alignment before arthrodesis is performed, and eventually avoid adverse events [9].

In the only prospective study on AARF [8], a subsequent C1-C2 fusion was performed in patients whose condition was refractory to conservative treatment or irreducible to halo traction. Pang and Li [8] also reported a high recurrence rate in chronic AARF, mainly in type 3 of Fielding and Hawkings, and taken this into consideration associated with the fact that the conservative treatment involves the long-term use of halo-vest, we decided to perform surgery. As our patient had no $\mathrm{C} 1$ posterior arch or $\mathrm{C} 2$ spinous process, fusion using transarticular screws, Goel [10] or Harms technique [11] would be the options to C1 and C2 fusion. The last one was our treatment of choice, followed by the use of a cervical collar for four weeks.

In conclusion, atlantoaxial subluxation is a pathological condition that can occur following surgical procedures that involve the mobilization of the head during general anesthesia or sedation, including neurosurgeries in the pediatric population. Early diagnosis and treatment prevent the evolution of AARF, but when this condition settles, surgical treatment is indicated, potentially preceded by traction using a cranial halo. Finally, the surgical technique to be used in each case should be carefully selected, considering the anatomical and bone conditions, as well as the surgeon's experience with each technique.

\section{Abbreviations}

AAARF - Atlantoaxial rotatory fixation

Declarations

\section{Ethics approval and consent to participate}

The case report of an individual case arise from a unplanned medical observation where there is no research project or objective previous defined. From this perspective, there is no possibility to obtain, from the Research Ethics Committee, a prior verification of its accomplishment. In accordance to Brazilian Ethical normative, in special, resolution $n^{\circ} 466 / 2012$, of the National Council of Health, from the Ministry 
of Health, only research projects involving human beings must attend to the relevant ethical and analyzed by an ethical committe, not medical observation. Considering the respect to the patient's dignity and autonomy it was obtained a deliberate consent statement from the patient and/or his/her legal representative following a model established by Neurosurgery Publishing Group Editorial Board. The document express patient agreement for images publication on Journal of Neurosurgery Publishing Group. Moreover, we provide procedures ensuring confidentiality and privacy, and image protection and use the material and data obtained from the patient solely for the purposes identified in participant's consent statement.

\section{Consent for publication}

The consent form for publication was obtained and signed by one of the parents of the children and by the first author.

\section{Availability of data and material}

The datasets used and/or analysed during the current study are available from the corresponding author on reasonable request.

\section{Competing interests}

The authors report no conflict of interest concerning the materials or methods used in this study or the findings specified in this paper.

\section{Funding}

No funds were received in support of this work.

No relevant financial activities outside the submitted work.

\section{Authors' contributions}

Conception and design: VMB. Acquisition of data: VMB. Analysis and interpretation of data: VMB and SC. Drafting the article: VMB and SC. Critically revising the article: VMB and SC. Reviewed submitted version of the manuscript: VMB and SC. Study supervision: VMB and SC. All authors have read and approved the manuscript.

\section{Acknowledgements}

The authors are grateful to the staff of the Neurosurgery Group for allowing the study of the patient and for their assistance with data collection.

\section{Authors' information}

1Department of Neurology and Neurosurgery, Paulista School of Medicine (EPM), Federal University of São Paulo (UNIFESP), São Paulo, Brazil. 


\section{References}

[1] Fielding JW, Hawkins RJ.: Atlanto-axial rotatory fixation. (Fixed rotatory subluxation of the atlantoaxial joint). J Bone Joint Surg Am 59: 37-44 (1977)

[2] Tauchi R, Imagama S, Ito Z, Ando K, Muramoto A, Matsui H, Matsumoto T, Ukai J, Kobayashi K, Shinjo $\mathrm{R}$, Nakashima H, Ishiguro N.: Atlantoaxial rotatory fixation in a child after bilateral otoplastic surgery. Eur J Orthop Surg Traumatol 24 Suppl 1: S289-292 (2014)

[3] Pang D, Li V.: Atlantoaxial rotatory fixation: Part 1--Biomechanics of normal rotation at the atlantoaxial joint in children. Neurosurgery 55: 614-625; discussion 625-616 (2004)

[4] Kelly EJ, Herbert KJ, Crotty EJ, O'Connor TP.: Atlantoaxial subluxation after otoplasty. Plast Reconstr Surg 102: 543-544 (1998)

[5] Meza Escobar LE, Osterhoff G, Ossendorf C, Wanner GA, Simmen HP, Werner CM.: Traumatic atlantoaxial rotatory subluxation in an adolescent: a case report. J Med Case Rep 6: 27 (2012)

[6] Deichmueller CM, Welkoborsky HJ.: Grisel's syndrome--a rare complication following "small" operations and infections in the ENT region. Eur Arch Otorhinolaryngol 267: 1467-1473 (2010)

[7] Don S.: Radiosensitivity of children: potential for overexposure in CR and DR and magnitude of doses in ordinary radiographic examinations. Pediatr Radiol 34 Suppl 3: S167-172; discussion S234-141 (2004)

[8] Pang D, Li V.: Atlantoaxial rotatory fixation: part 3-a prospective study of the clinical manifestation, diagnosis, management, and outcome of children with alantoaxial rotatory fixation. Neurosurgery 57: 954-972; discussion 954-972 (2005)

[9] Ahmed R, Traynelis VC, Menezes AH.: Fusions at the craniovertebral junction. Childs Nerv Syst 24: 1209-1224 (2008)

[10] Goel A, Laheri V.: Plate and screw fixation for atlanto-axial subluxation. Acta Neurochir (Wien) 129: 47-53 (1994)

[11] Harms J, Melcher RP.: Posterior C1-C2 fusion with polyaxial screw and rod fixation. Spine (Phila Pa 1976) 26: 2467-2471 (2001)

\section{Figures}




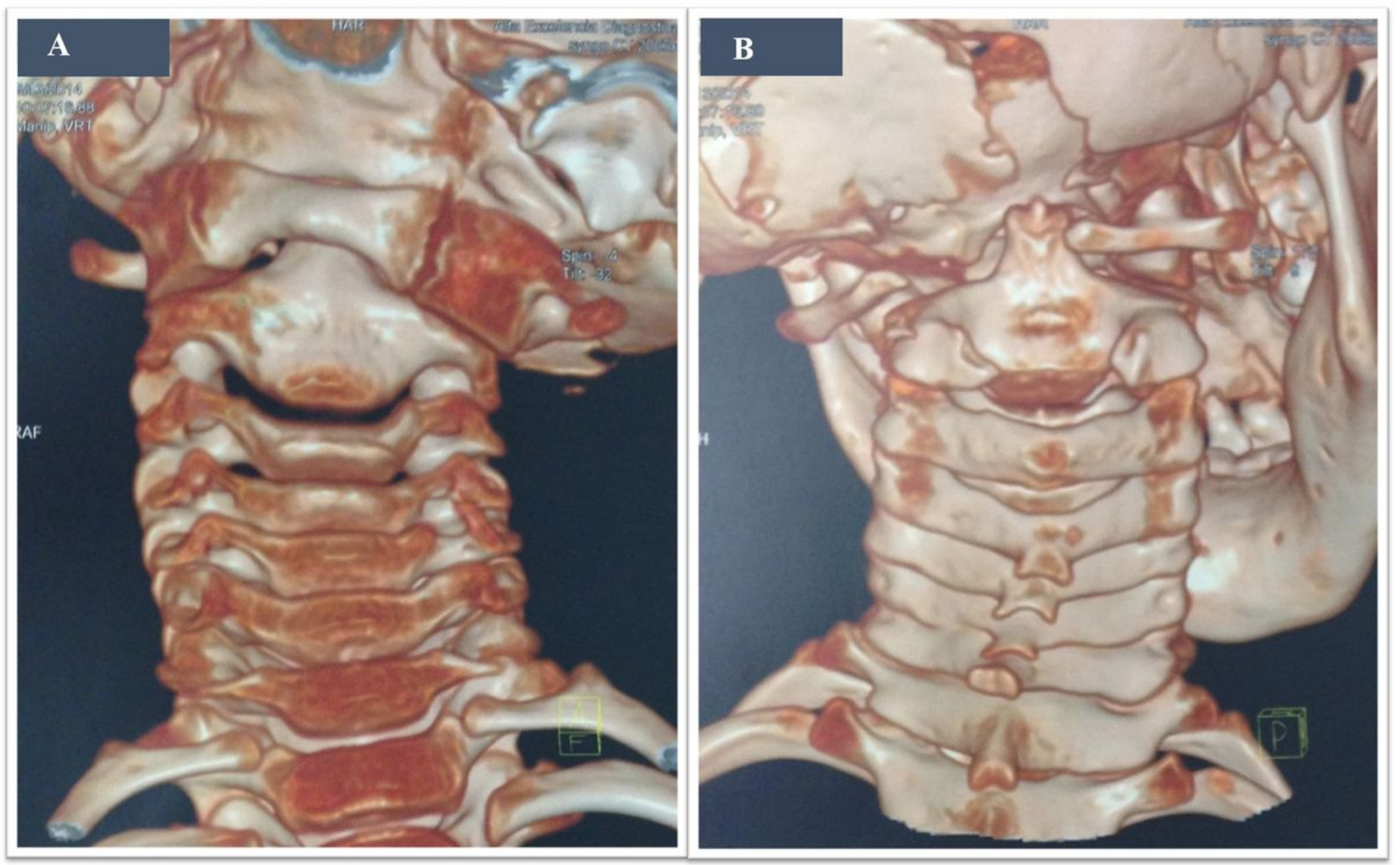

\section{Figure 1}

Presence of AARF condition. Three-dimensional computed tomography of the cervical spine demonstrating a type 3, left, anterior, fixed atlantoaxial rotatory subluxation. C2-C3 subluxation is also evident, without any commitment of neurovascular structures (A). Previously removal of the posterior arch of the atlas (C1), spinous process, and part of the $\mathrm{C} 2$ lamina can be seen (B). 


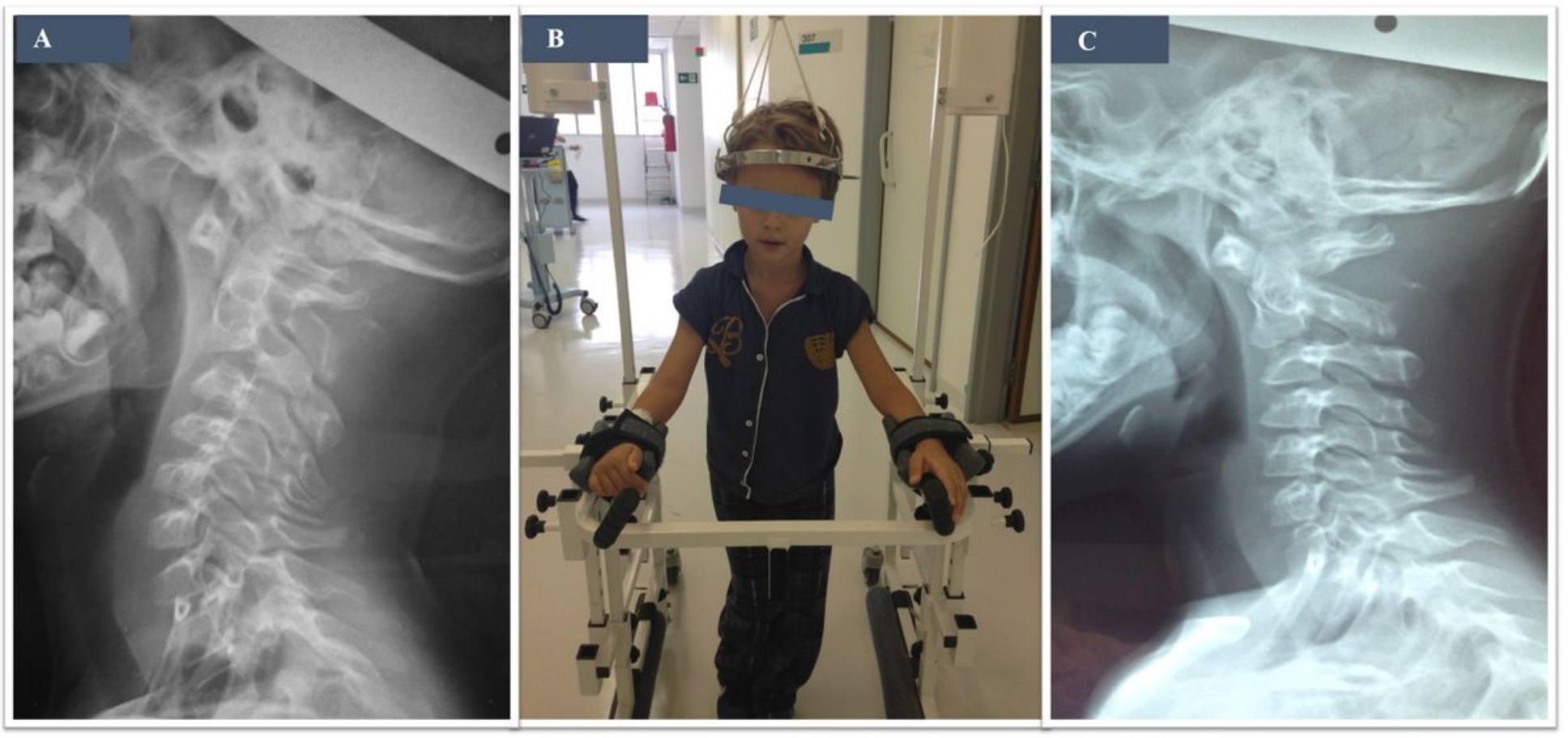

Figure 2

Performance of halo-gravity traction. Radiography of the cervical spine is demonstrating the presence of a halo traction device, placed immediately after diagnosis of AARF, to perform continuous cranial traction (A). Patient during the treatment with a halo traction walker (B). Radiography of the cervical spine after 14 days showing neck position alignment and reduction of joint subluxation and joint distraction between the posterior elements of $\mathrm{C} 1$ and $\mathrm{C} 2$ (C). 


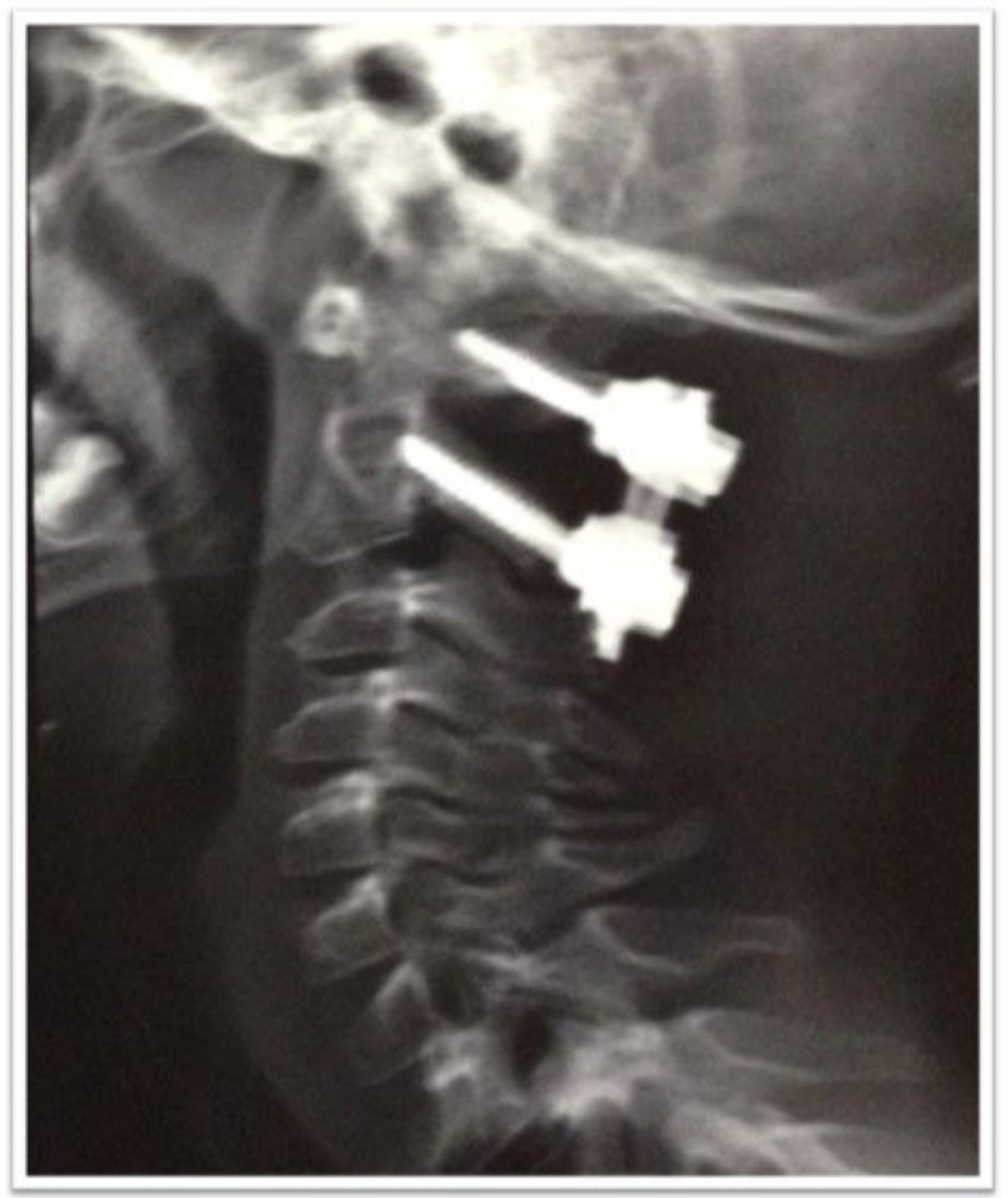

\section{Figure 3}

C1-C2 stabilization using the Harms technique. Postoperatively, plain radiography showing atlantoaxial fixation using the Harms technique, which consists of C1-C2 stabilization with polyaxial screws and rods. Cervical spine appears satisfactorily aligned after hardware placement comprising C1-C2. 


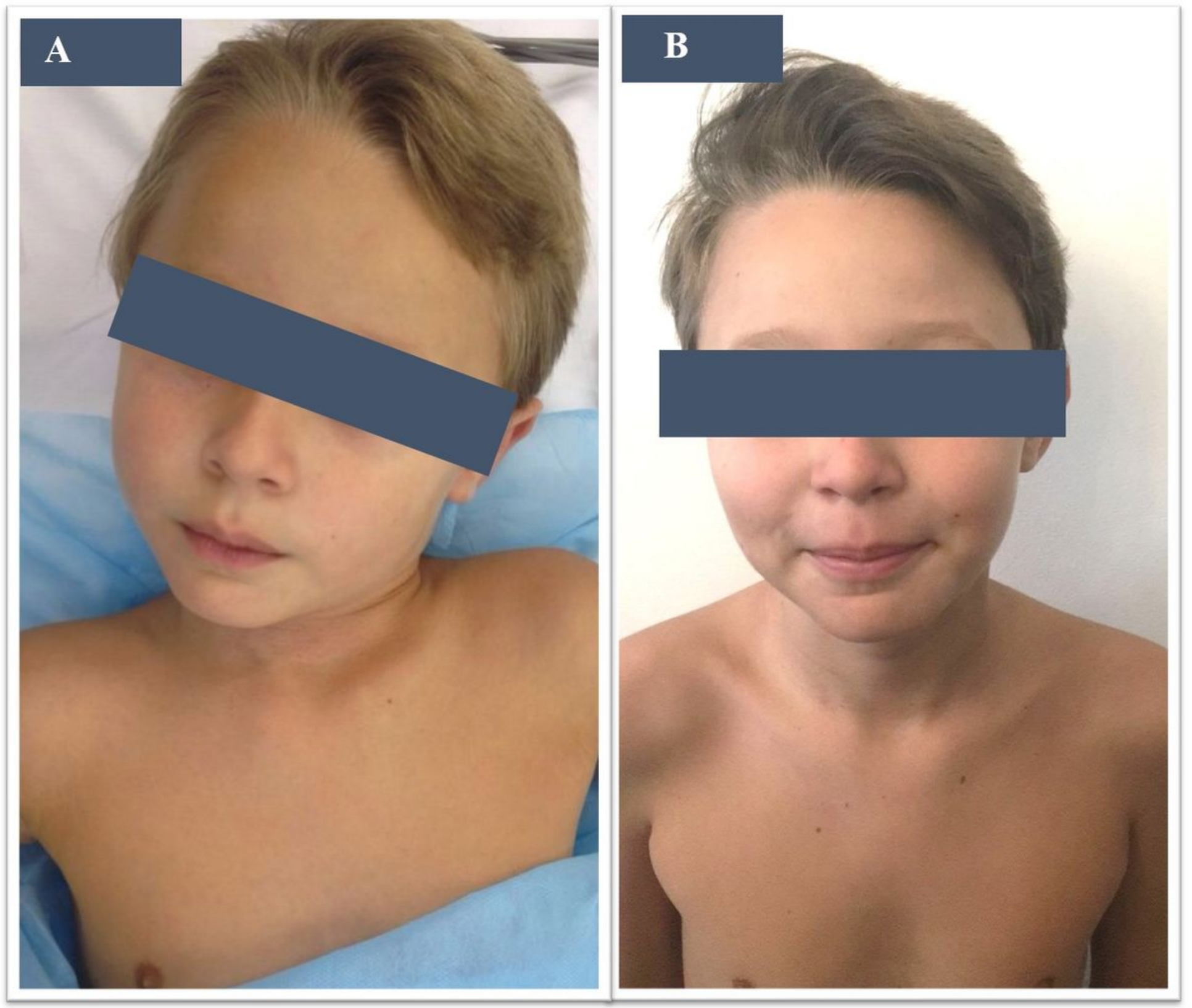

\section{Figure 4}

Pre- and postoperative images of the patient. The patient is showing typical torticollis, with left, anterior fixed rotation of the neck, demonstrating Cock Robin position (A). Four years postoperatively, patient image showing reduction of the abnormal neck position presented previously (B).

\section{Supplementary Files}

This is a list of supplementary files associated with this preprint. Click to download.

- Checklist.pdf 